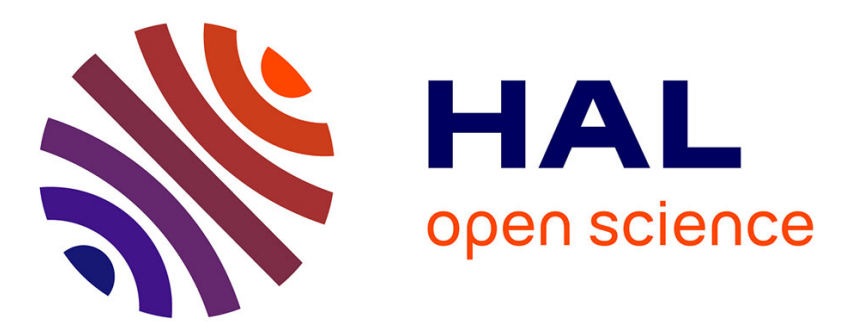

\title{
Methodology for service life increase of hot forging tools
}

Olivier Brucelle, Gérard Bernhart

\section{To cite this version:}

Olivier Brucelle, Gérard Bernhart. Methodology for service life increase of hot forging tools. Journal of Materials Processing Technology, 1999, 87 (1-3), pp.237-246. 10.1016/S0924-0136(98)00357-4 . hal-01701676

\section{HAL Id: hal-01701676 \\ https://hal.science/hal-01701676}

Submitted on 11 Jan 2019

HAL is a multi-disciplinary open access archive for the deposit and dissemination of scientific research documents, whether they are published or not. The documents may come from teaching and research institutions in France or abroad, or from public or private research centers.
L'archive ouverte pluridisciplinaire HAL, est destinée au dépôt et à la diffusion de documents scientifiques de niveau recherche, publiés ou non, émanant des établissements d'enseignement et de recherche français ou étrangers, des laboratoires publics ou privés. 


\title{
Methodology for service life increase of hot forging tools
}

\author{
Olivier Brucelle, Gérard Bernhart* \\ Ecole des Mines d'Albi-Carmaux, Material Research Center, Route de Teillet, 81013 ALBI CT Cedex 09, France
}

\begin{abstract}
Hot forging is widely used in the manufacturing of automotive components. The high production rate induces severe thermomechanical stresses in the tools. The lifetime of dies is commonly driven either by wear or thermal cracking. This paper describes the methodology that has been applied to gain understanding of the thermomechanical stress field in a cemented carbide punch used for the manufacture of airbag container type parts. The stresses are the result of a combination of purely mechanical stresses due to the forging process, and thermomechanical stresses induced by the thermal cycling of the punch surface during successive hot forging and waiting periods. Simulation results have been validated as a result of experimental investigations. The results show that in the critical area subjected to thermal cracking, the thermomechanical stress contribution is as high as $75 \%$ of the total stress field. As a consequence, it has been determined that an increased tool life could be expected by a global modification of the nominal hot-forging process parameters, i.e. by the modification of billet temperature and forging rate.
\end{abstract}

Keywords: Hot forging; Thermal cracking; Tools; Dies; Service life; Numerical simulation

\section{Introduction}

Subcontractors and suppliers are increasingly under pressure with regard to cost reduction and responsibility for the development of new components. This is particularly critical in the automotive industry [1]. As a result, they need to gain increased technical skills in the areas of material science and metallurgy, in process definition simulation, as well as in the design of components and tools. Knowledge of computer aided design and numerical calculation also becomes mandatory.

In the forging industry, the tooling cost can constitute up to $50 \%$ of the component total cost. With regard to this proportion, it becomes obvious that component cost reduction requires an optimization of the dies, and in particular, an increase in performance and service life. Much work has been done in this direction for cold-forging tools [2] [3] where an increase of lifetime is often obtained by a reduction of the stress levels through a modification of the tool design. The use of adequate coatings or surface treatment is another way to increase die life.

\footnotetext{
* Corresponding author. Fax: + 330563 493099; e-mail: bernhardt@enstimac.fr.
}

During hot-forging processes, the tools are not only subjected to mechanical stresses, but also to thermomechanical stresses that are induced by the thermal cycling and the result of successive forging steps and waiting periods. This cycling initiates tool damage that is known as heat checking. With regard to thermal stresses, it is well known that a change in the geometry is generally not the best way to reduce the stress level.

This paper describes the methology that has been followed to increase the tool service life of a cemented carbide punch for the manufacture of airbag type parts. The importance of a simultaneous use of numerical simulation (process simulation and thermomechanical stress calculation) and experimental testing (laboratory and industrial tests) is highlighted. The industrial problem and the recommended modifications of the process parameter are presented.

\section{Description and analysis of the industrial problem}

The airbag component is manufactured in a one-step forward/backward hot-forging operation. The initial workpiece, made of austenitic stainless steel AISI 316L, 


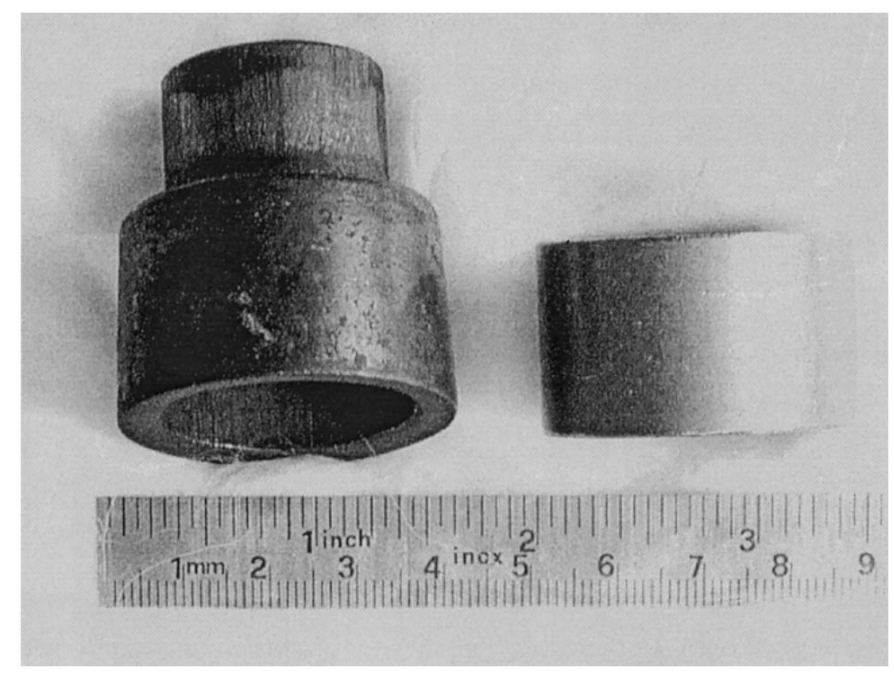

Fig. 1. Final and initial shape of the workpiece.

and the final shape of the part are presented in Fig. 1. The tooling system (Fig. 2) includes several pieces; amongst them a cemented carbide punch on which the present study is focused. The forging operation is performed with a $200 \mathrm{t}$ press, with the workpiece initially at $1000^{\circ} \mathrm{C}$. The drop of the punch is done in $0.3 \mathrm{~s}$ and the effective contact duration between the tool and the billet is $\approx 30 \mathrm{~ms}$.

After a few hundred forging operations, the punch shows [4] (Figs. 3 and 4) a circumferential crack at the fillet radius 2 and a network of cracks at the shoulder 3 . After $\approx 500$ cycles, a coalescence of cracks occurs near to shoulder 3 and initiates surface damages by splitting off: the punch has to be changed at this time.

The crack at fillet radius 2 is a 'mechanical induced' crack, in contrast to the network at shoulder 3, which

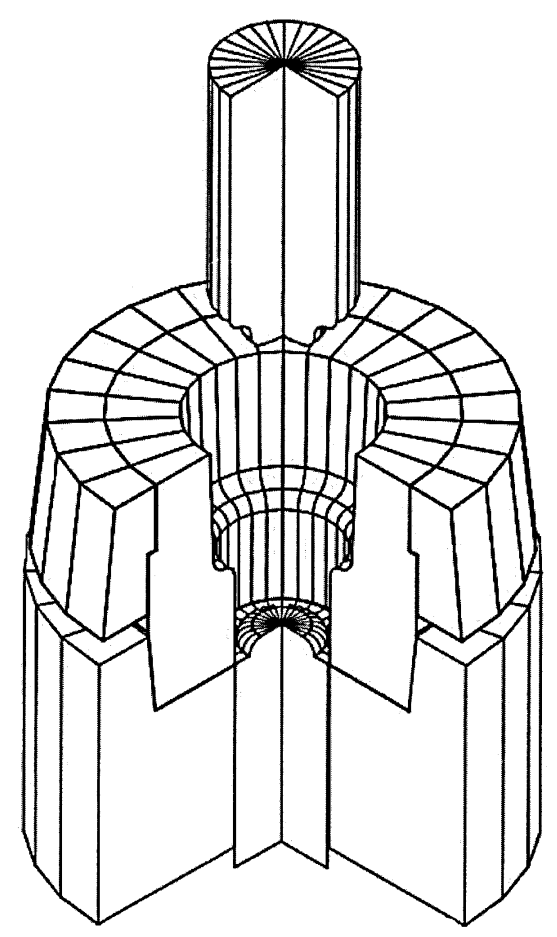

Fig. 2. Tooling system.

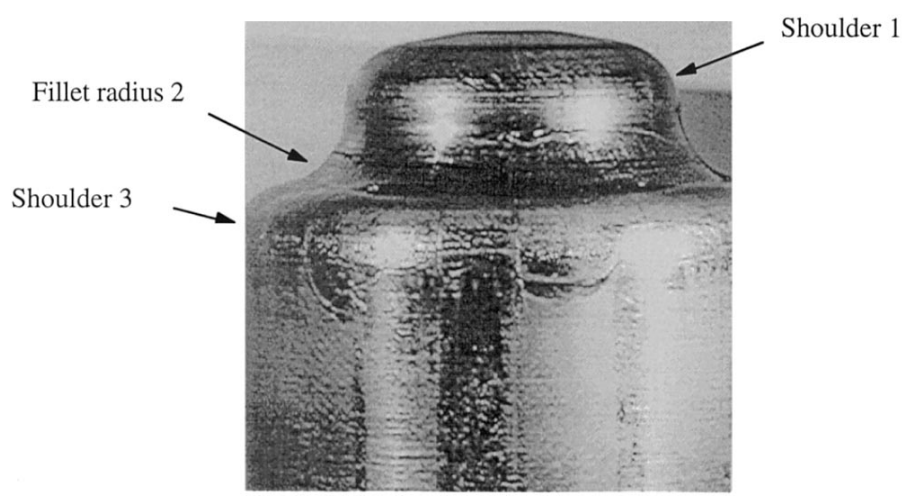

Fig. 3. Crack network of the punch.

corresponds to what is commonly called 'heat checking'. This type of damage is the result of constraints generated by high thermal gradients. During forging, the surfaces of the dies are subjected to a thermal flux

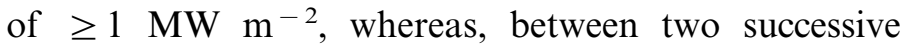
operations, the surface temperature drops. Locally, the surfaces of the tools are subjected to thermomechanical fatigue (TMF) cycling which can exceed the purely elastic-behaviour domain, and cause the initiation of cracks.

Thermal fatigue is the result of a partially or completely constrained thermal expansion [5]. It can be the result of internal constraints due to thermal gradients or material heterogeneities, and external constraints due to the mechanical loads on the surface [6]. In this paper, the two types of constraints are superimposed; moreover, this is the general case encountered in such type of industrial problems.

\section{Methodological approach}

\subsection{General description of the methodology}

The problem has been solved in the following way (Fig. 5):

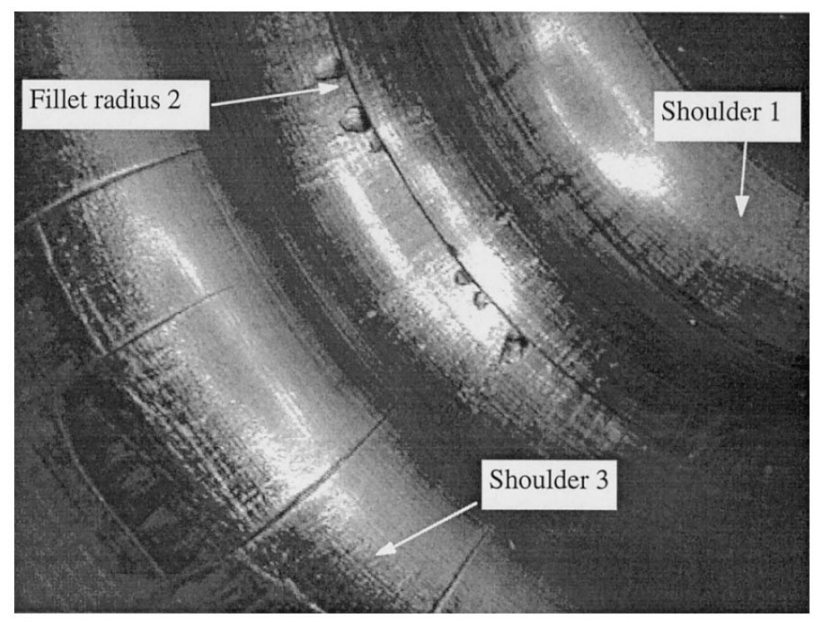

Fig. 4. Details of cracking. 


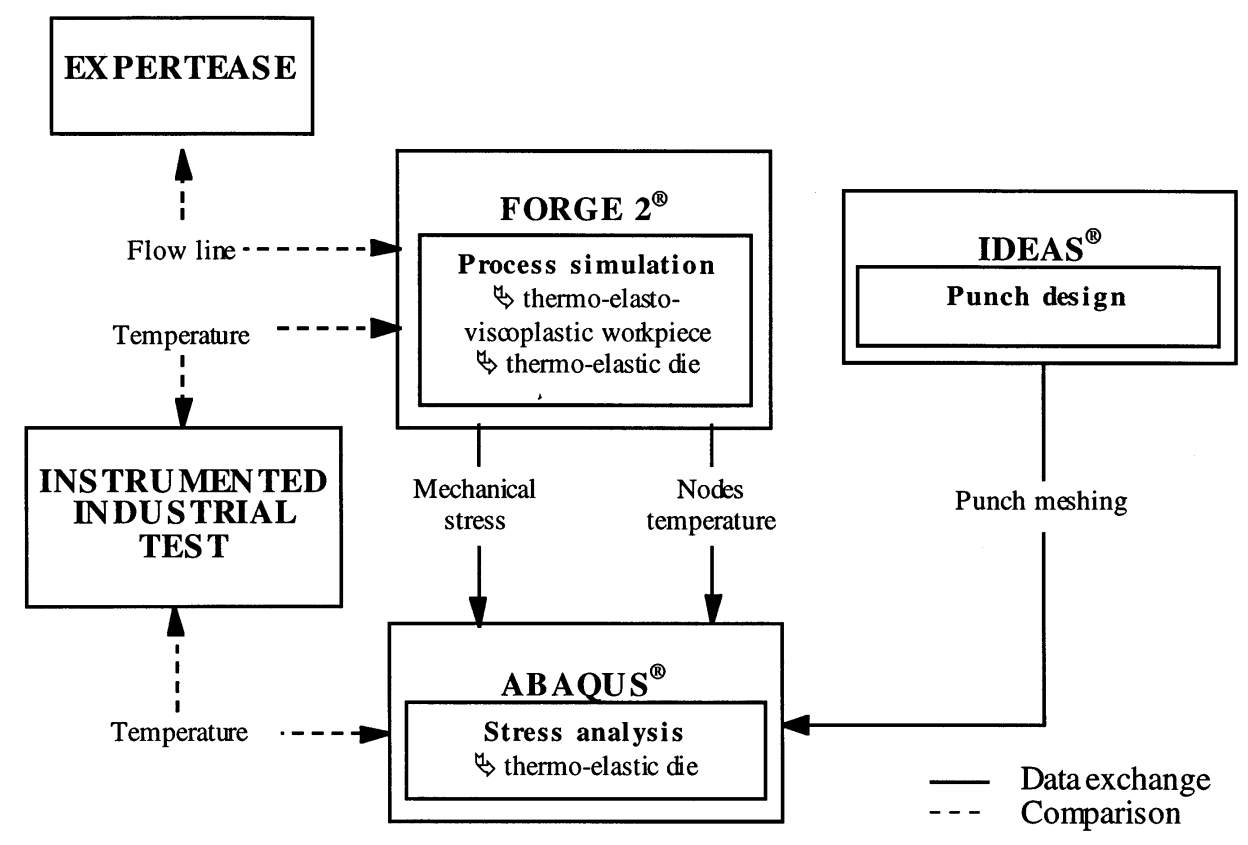

Fig. 5. Methodological approach.

1. The forging process was simulated with the FORGE2 ${ }^{\circledR}$ computer code. No coupling was made intentionally between the mechanical and thermal loads. The results are the purely mechanical stresses in the punch and the evolution of the surface temperature of the punch;

2. After meshing with IDEAS ${ }^{\circledR}$ software, the thermal stresses of the punch have been calculated with ABAQUS ${ }^{\circledR}$;

3. Validation of the two previous simulations have been performed by experimental tests.

In more detail, the methodological approach combines nine steps:

step 1: mesh generation of the workpiece and the punch with the integrated mesh generation tool of FORGE2 ${ }^{\circledR}$

step 2: tool data file definition (punch forging speed, number of tools, geometries,...),

step 3: FORGE2 ${ }^{\circledR}$ input data file definition (material properties, interface properties,...) and process simulation,

step 4: validation of step 3 through the expertise of a forged part. The calculated flow-line is compared to the observed flow-line with the aim of validating the material flow during the forging operation and, as a consequence, the process simulation step for the part related to the mechanical loads. step 5: postprocessing of the FORGE2 ${ }^{\circledR}$ results and extraction of the temperature-time evolution laws on the punch surface nodes,

step 6: punch thermal mesh generation with IDEAS ${ }^{\circledR}$ software,

step 7: ABAQUS ${ }^{\circledR}$ input data file preparation for the thermoelastic calculation of the punch thermomechnical stress distribution,

step 8: validation of the thermal gradients at the punch surface. For this, thermal measurements with an instrumented punch have been made on the industrial facility and are compared to the calculated values. This step validates, in particular, the die/ workpiece heat transfer coefficient.

step 9: post-processing of ABAQUS ${ }^{\circledR}$ results: thermal stress distribution in the punch.

\subsection{Forging process simulation and validation}

General description of the FORGE2 ${ }^{\circledR}$ process simulation tool can be found in [7]. During simulation, four components are taken into account: three tooling components and the workpiece. The elements related to the lower die and the ejector are considered as rigid bodies, the punch is assumed to have thermo-elastic behaviour and the workpiece to have thermo-elasto-viscoplastic behaviour.

Table 1

Physical properties of the punch materials

\begin{tabular}{lllllll}
\hline Material & $E(\mathrm{GPa})$ & $v$ & $\rho\left(\mathrm{g} \mathrm{cm}^{-3}\right)$ & $C_{\mathrm{p}}\left(\mathrm{J} \mathrm{kg}^{-1} \mathrm{~K}^{-1}\right)$ & $\mathrm{K}\left(\mathrm{W} \mathrm{m}^{-1} \mathrm{~K}^{-1}\right)$ & $\alpha\left(10^{-6}{ }^{\circ} \mathrm{C}^{-1}\right)$ \\
\hline WC-Co 85-15 & 530 & 0.23 & 14 & 220 & 100 & 5.8 \\
X85WCrMoV6-5-4-2 & 216 & 0.29 & 8.15 & 439 & 20 & 12 \\
\hline
\end{tabular}




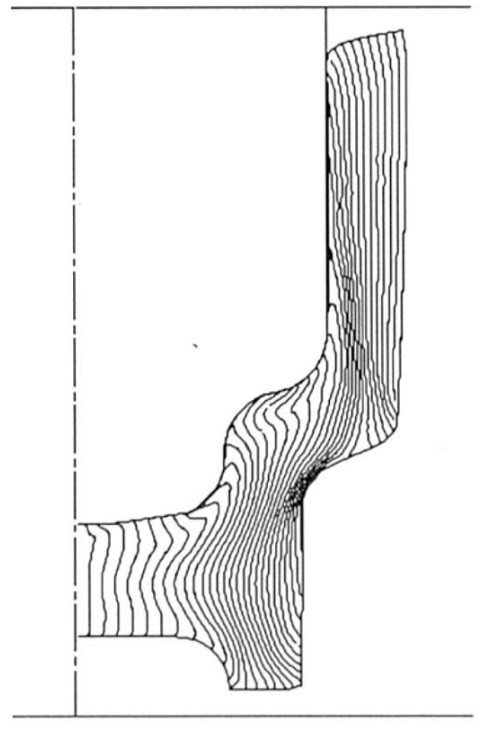

Simulation

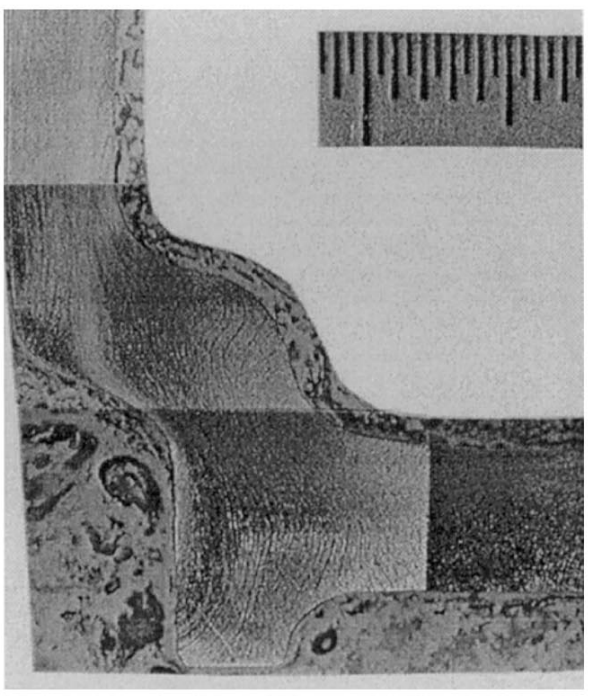

Experimental

Fig. 6. Flow line comparison.

The physical properties of the punch materials are listed in Table 1.

The elastic behaviour of the billet material is described by assuming that its Youngs modulus follows a linear law with temperature in the form:

$E=E_{0} \cdot(1-a T) \quad$ where $E_{0}$ and $a$ are constants.

A Norton-Hoff law is used to describe the viscoplastic behaviour. In FORGE2 ${ }^{\circledR}$ the tensorial formulation is:

$s=2 \cdot K(T, \bar{\varepsilon}) \cdot(\sqrt{3} \cdot \dot{\bar{\varepsilon}})^{m-1} \cdot \dot{\varepsilon}$

where:

$K(T, \bar{\varepsilon})=K_{0} \cdot\left(\bar{\varepsilon}+\bar{\varepsilon}_{0}\right)^{n} \cdot \mathrm{e}^{-\beta \cdot T}$

$\beta, K_{0}$ and $\bar{\varepsilon}_{0}$ are constants, $T$ is temperature, $K$ is consistency, $m$ is the strain-rate exponent, $s$ is the stress deviator, $\bar{\varepsilon}$ is the effective strain, $\dot{\bar{\varepsilon}}$ is the effective strain-rate and $n$ is the hardening coefficient.

The corresponding AISI $316 \mathrm{~L}$ material parameters are listed in Table 2 [7].

The interface description between the tool and the workpiece takes into account the three following aspects: contact, friction and heat transfer. The friction law used during simulation is the Coulomb law limited by Tresca shear stress:

$$
\begin{array}{ll}
\|\tau\|=\mu \cdot \sigma_{n}, & \text { if } \mu \cdot \sigma_{\mathrm{n}}<\bar{m} \cdot \frac{\sigma_{0}}{\sqrt{3}} \\
\|\tau\|=\bar{m} \cdot \frac{\sigma_{0}}{\sqrt{3}}, & \text { if } \mu \cdot \sigma_{\mathrm{n}}>\bar{m} \cdot \frac{\sigma_{0}}{\sqrt{3}}
\end{array}
$$

with:

$\sigma_{\mathrm{n}}=\sqrt{3} \cdot K(\bar{\varepsilon}, T) \cdot(\sqrt{3} \cdot \dot{\bar{\varepsilon}})^{m}$

where $\bar{m}$ is the shear friction factor; $\mu$ is the Coulomb friction coefficient; $\sigma_{0}$ is the flow stress; $\tau$ is the friction shear stress; and $\sigma_{\mathrm{n}}$ is the normal stress at the interface.

The heat exchange at the interface boundary involves conductive heat-transfer and dissipative energy due to friction. Radiative transfer is negligible.

A comparison was made between the predicted workpiece flow-line and the observed flow-line on a sectioned airbag part, after etching. The similarity of the two figures (Fig. 6) validates the material constitutive laws and tribological laws used for simulation.

As a consequence, the purely mechanical stresses in the punch are available.

\subsection{Thermal stress analysis}

The thermomechanical stress analysis is only focused on the punch and is performed with ABAQUS ${ }^{\circledR}$ software to obtain a more precise analysis of the thermal

AISI 316L material parameters

\begin{tabular}{llllll}
\hline$E_{0}(\mathrm{GPa})$ & $a\left({ }^{\circ} \mathrm{C}^{-1}\right)^{1}$ & $\beta\left({ }^{\circ} \mathrm{C}^{-1}\right)$ & $n$ & $K\left(\mathrm{~kg} \mathrm{~m}^{-1} \mathrm{~s}^{-1.936}\right)$ & $m$ \\
\hline 216 & $-3.773 \times 10^{-4}$ & $0.215 \times 10^{-2}$ & 0.205 & $0.1777 \times 10^{7}$ & $0.6400 \times 10^{-1}$ \\
\hline
\end{tabular}




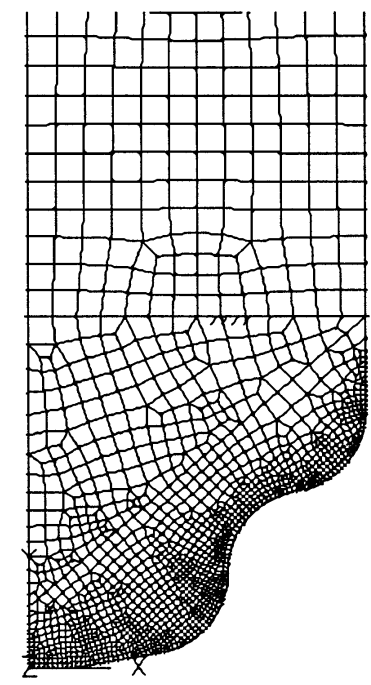

Fig. 7. Punch meshing.

gradient and the induced thermal stresses. For this, a special mesh, refined near to the surface, has been generated with IDEAS ${ }^{\circledR}$ software (Fig. 7). The punch is considered as thermo-elastic, and only a thermal load case analysis is performed. This load case is defined by the thermal evolution at the surface nodes: temperature-time profiles during forging, derived from the process simulation, and a low convective flux during the waiting periods.

\subsection{Experimental punch temperature monitoring}

It is of prime importance to be confident with the temperature distribution inside the punch during successive forging operations. The calculated surface temperatures are directly linked to the heat-transfer coefficient at the tool/workpiece interface. It is known that the heat-transfer coefficient is affected by numerous factors [8]; amongst them the more important being contact pressure, the surface topography, duration of contact and temperature difference level.

A punch was instrumented with type $\mathrm{K}$ thermocouples; for practical and economical reasons, a tool steel (X85WCrMoV6-5-4-2) was used for the manufacture of the test punch. After preliminary simulations (with thermal properties of this type of material, see Table 1), five thermocouples were located in the test punch as shown in Fig. 8, some of them at $1 \mathrm{~mm}$ beneath the surface. The tests were been performed on an industrial press without any lubricant.

Data acquisition during testing was performed with a computer system at a rate of $100 \mathrm{~Hz}$. Typical experimental evolution of the thermal response at the various locations in the test punch are presented in Fig. 9. It can be noted that in the punch itself, the thermal wave is smoothed and shifted in time, in comparison with the $30 \mathrm{~ms}$ duration of contact.
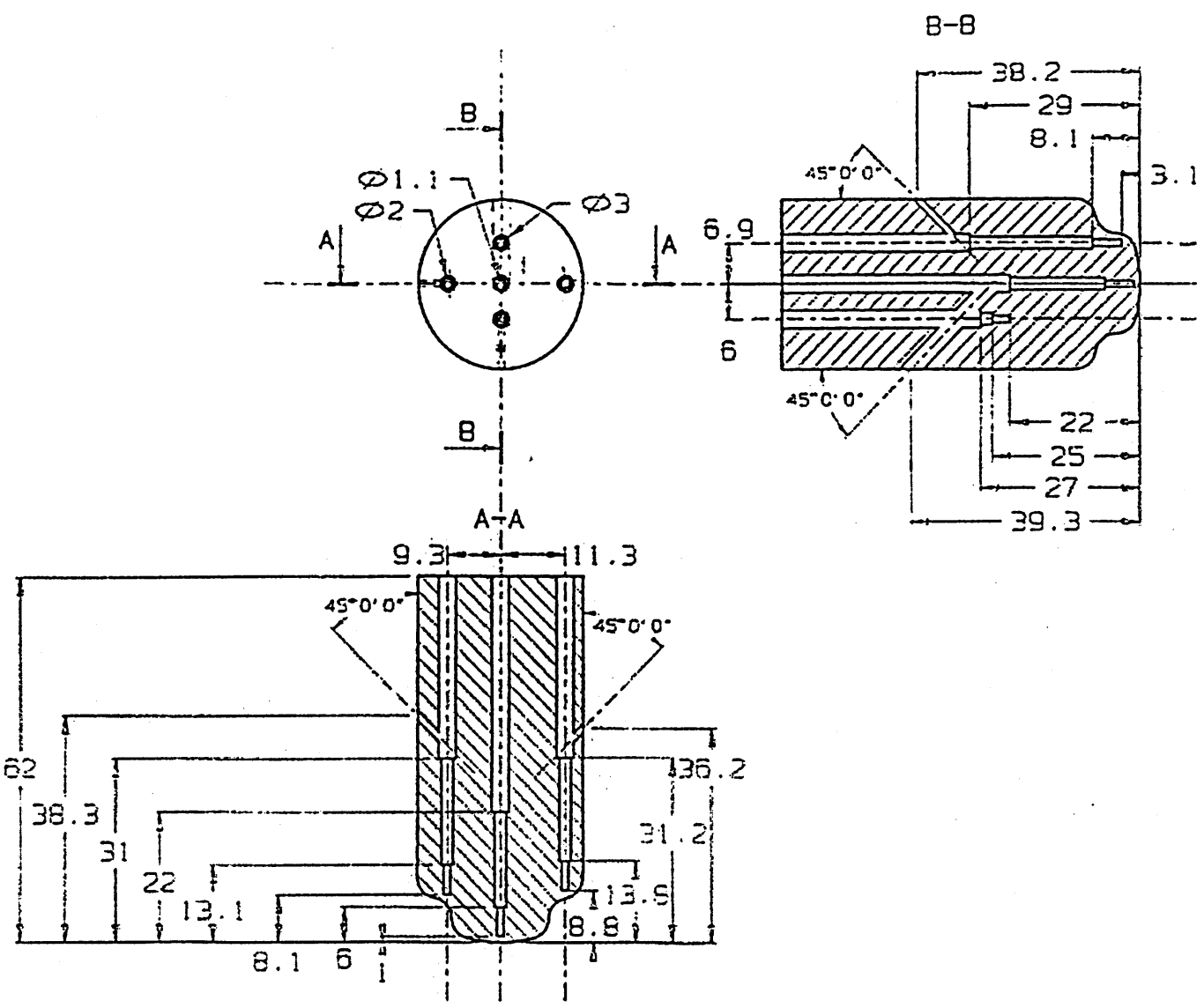

Fig. 8. Thermocouple location. 


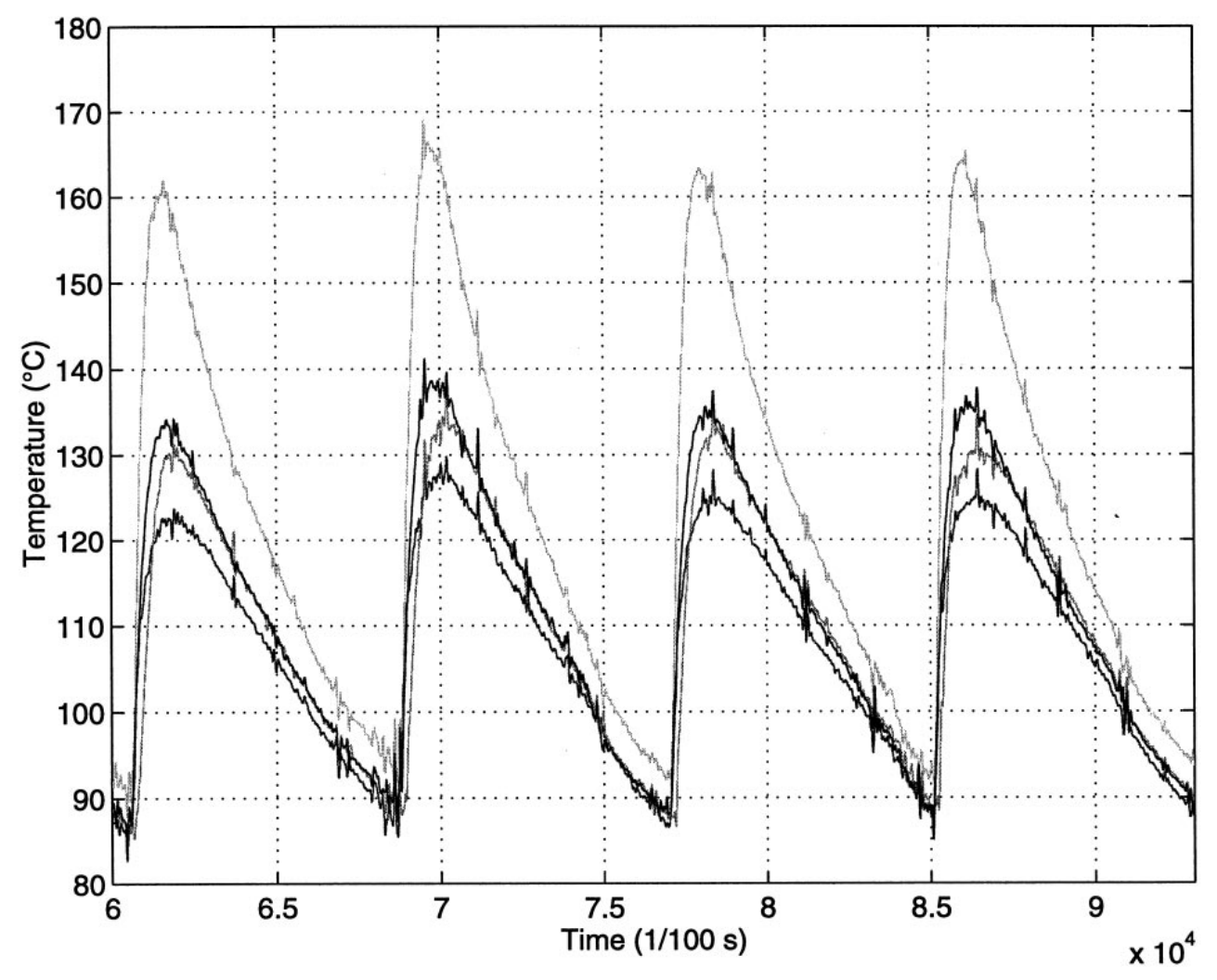

Fig. 9. Experimental temperature evolution.

Successive numerical iterations have been performed changing the value of the heat-transfer coefficient, until the calculated temperature evolution was in agreement with the experimental thermocouple response. As a result, a value of $15 \mathrm{~kW} \mathrm{~m} \mathrm{~m}^{-1} \mathrm{~K}^{-1}$ was identified as heat transfer coefficient for the definition of the cemented carbide punch thermal load case. Reference [9] reports such a value for high contact pressure and high temperature difference $\left(1000^{\circ} \mathrm{C}\right)$.

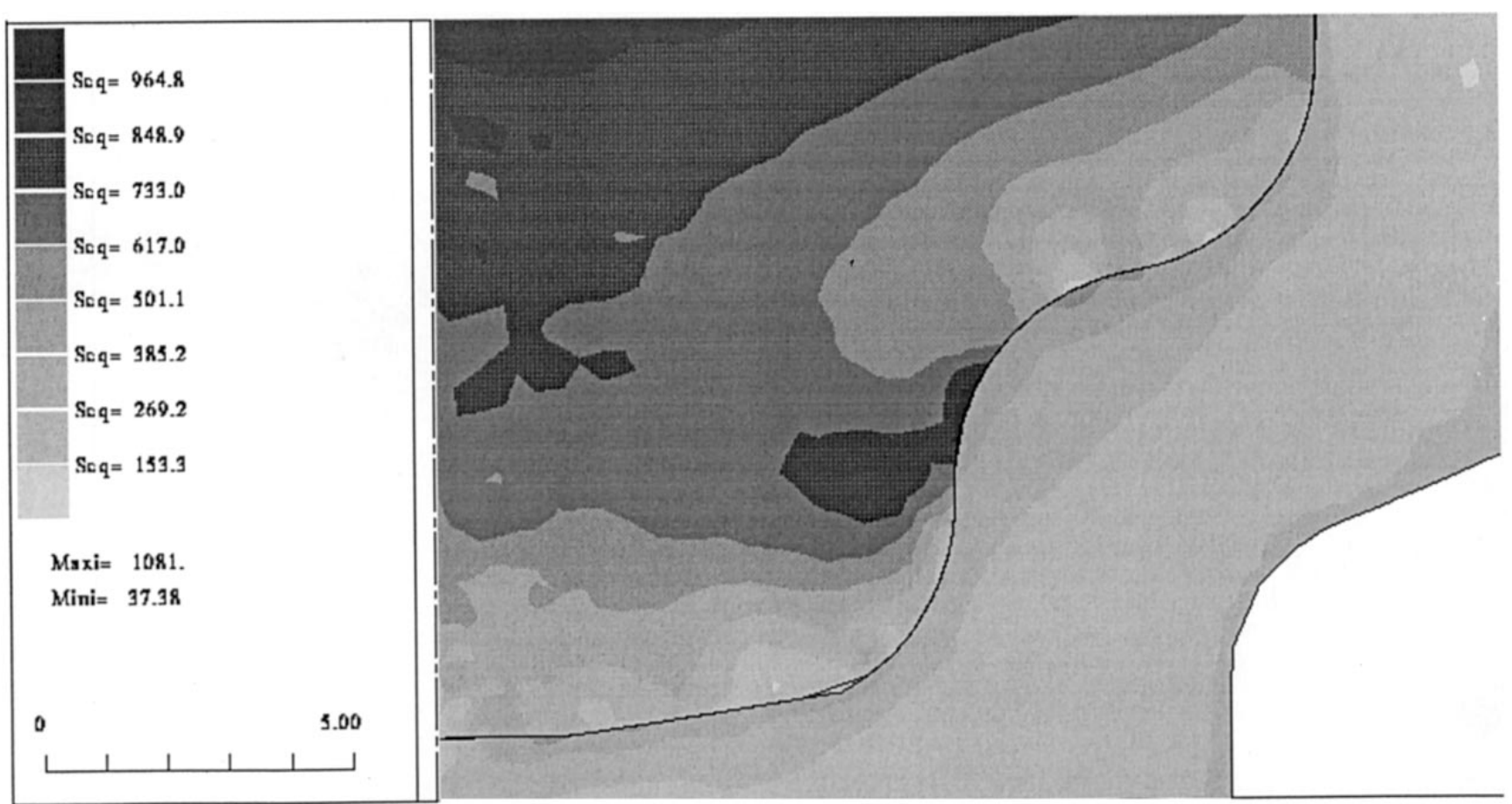

Fig. 10. Von Mises mechanical stress (MPa). 


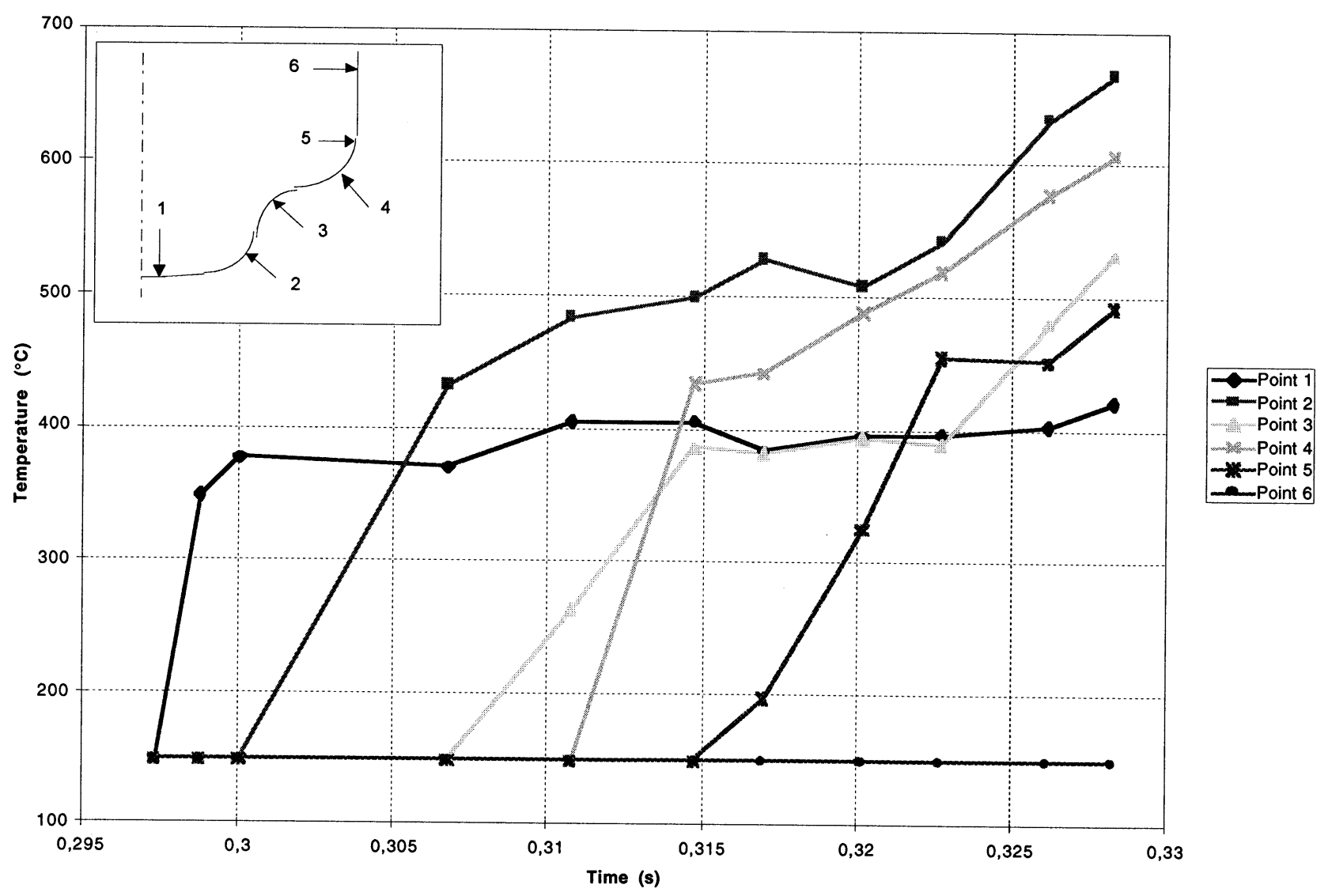

Fig. 11. Simulated temperature evolution.

\section{Results and discussion}

\subsection{Mechanical and thermomechanical stress distribution}

The purely mechanical stresses in the punch are compressive stresses, and the equivalent Von Mises stress distribution in the punch as shown in Fig. 10, for the maximum forging load. Near to the surface, the stresses are generally low $(\approx 200-300 \mathrm{MPa})$, except in fillet radius 2 and at the end of shoulder 3 , where they reach a level of 600-700 $\mathrm{MPa}$.

Temperature profiles on the punch surface are plotted for different points in Fig. 11. These temperatures can reach $700^{\circ} \mathrm{C}$ at shoulder 3 (point 4 ) and shoulder 1 (point 2), with the evolution versus time being different at each location. The temperature distribution in the punch at the end of the forging step is illustrated in Fig. 12. The sharp thermal gradient induces high thermal stress distribution, shown in Fig. 13. The stresses are compressive on the surface, the equivalent stresses reaching a value of $1360 \mathrm{MPa}$.

If the type of stresses is explores more closely, it can be seen that the highest levels are located at the same places as the cracks, and that: (i) at fillet radius 2 , the maximal stresses are compressive in the $z z$ direction (punch motion direction) having a level of $-2450 \mathrm{MPa}$ ( $-1050 \mathrm{MPa}$ from the mechanical and $-1400 \mathrm{MPa}$ from the thermal stress); and (ii) at shoulder 3, the maximum stresses are compressive in the circonferential direction (along the outer diameter of the punch), reaching a level of $-2300 \mathrm{MPa}(-700 \mathrm{MPa}$ from the mechanical and $-1600 \mathrm{MPa}$ from the thermal stress).

\subsection{Discussion}

\subsubsection{Cemented carbide behaviour}

Cemented carbide material properties are linked closely to the Co content and the WC particle size. In tension and compression, the $\mathrm{WC}-\mathrm{Co}$ composite exhibits an elasto-plastic behaviour. The onset of plastic deformation depends on the material composition, as shown in [10]. The punch is manufactured with a $85-15$ WC-Co material. SEM investigations have shown that the mean particle size is close to $2.5 \mu \mathrm{m}$ (Fig. 14).

For such compositions, reference [10] reports a true elastic limit (at $0.002 \%$ ) of $1050 \mathrm{MPa}$ and a conventional limit (at $0.2 \%$ ) of elasticity of $3100 \mathrm{MPa}$ at room temperature. The elastic and rupture properties decrease slowly up to $600^{\circ} \mathrm{C}$, whereas at higher temperature, a modification of the stress-strain curve is observed [11].

A stress level of $2400 \mathrm{MPa}$, as calculated previously, corresponds to a plastic deformation as high as $0.1 \%$ when related to room temperature properties and probably much higher at $700^{\circ} \mathrm{C}$. As a consequence, the 


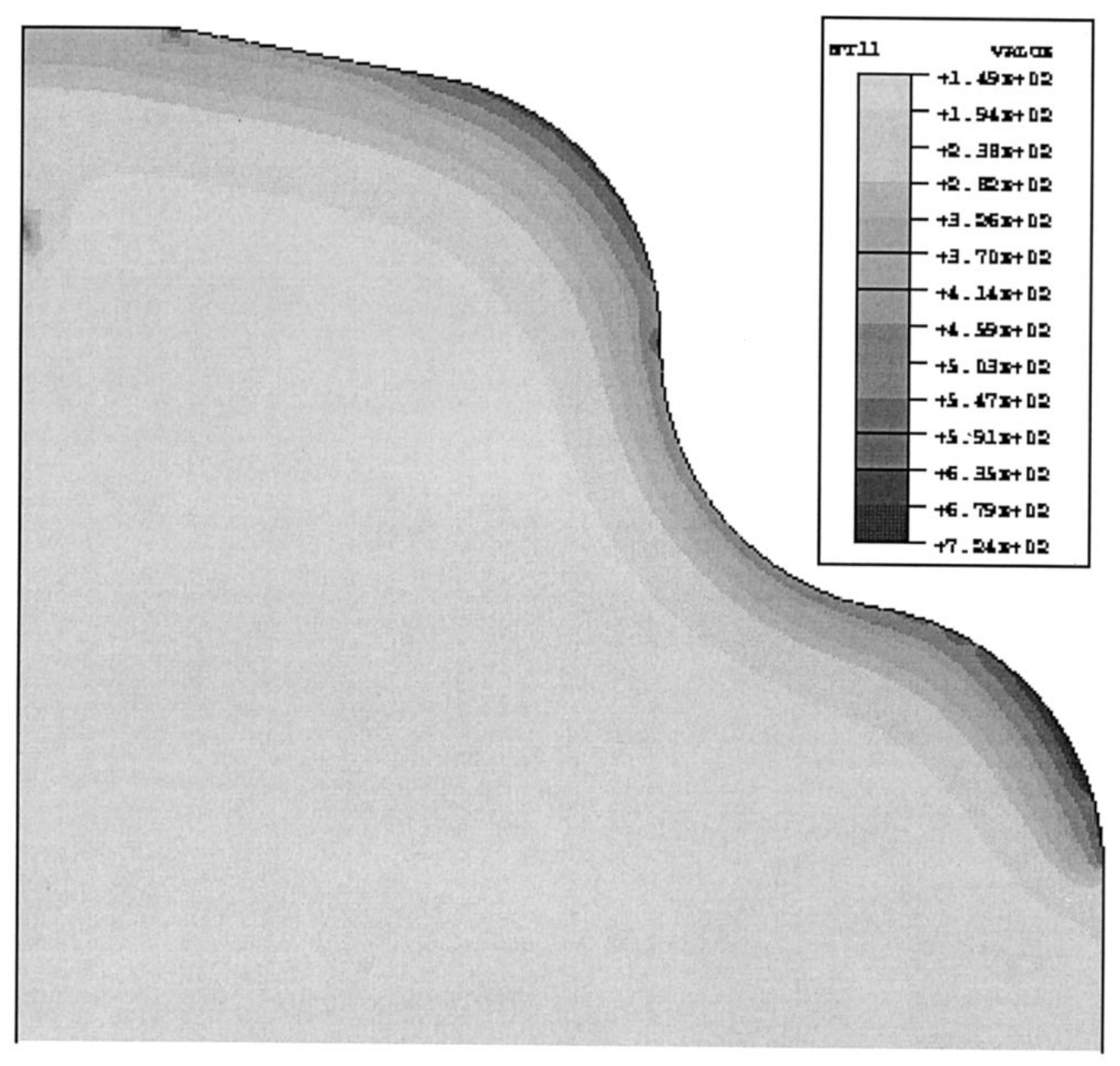

Fig. 12. Temperature distribution $\left({ }^{\circ} \mathrm{C}\right)$.

material is subjected to low cycle fatigue which is able to induce cracks after a limited number of cycles.

\subsubsection{Options for service life increase}

Without taking into account punch material changes and coatings, service life increase requires a decrease in the stress and temperature level in the punch. The thermal stresses are as high as $75 \%$ of the total stress field in the critical areas of the punch; as a consequence, a reduction of the thermal gradient during forging must be obtained.

Two ways may be used; the first involving a change of the process parameters to decrease the temperature. This solution is based on the following points: (i) a decrease of the workpiece temperature increases the flow stress and the related forging load. However, the capacity of the available press is much greater than needed: (30 t used out of $200 \mathrm{t}$ available); and (ii) a decrease of the punch speed allows a decrease of the flow stress. The second way consists of using lubricating/insulating products during forging to decrease workpiece/die heat transfer. The selection of an adequate product remains empirical even though it has been shown that a decrease of $50 \%$ of the heat transfer coefficient can be reached [12]. The first option was followed in this study.

\subsubsection{Process parameter modification}

Taking into account the capacities of the industrial press, a numerical parametric study has been performed, and the influence of the forging speed and the initial workpiece temperature on the final thermomechanical stresses have been studied. An optimum has been found for the following conditions: initial workpiece temperature, $500^{\circ} \mathrm{C}$; forging speed decreased by a factor of 1.5 .

With these process parameters, the forging load is $\approx 140 \mathrm{t}$ and the maximum punch surface temperature is close to $600^{\circ} \mathrm{C}$ in shoulder 3 . The resulting thermal stress distribution is shown Fig. 15. The maximum equivalent Von Mises stress is close to $1000 \mathrm{MPa}$ which corresponds to a decrease of $30 \%$. Circonferential and longidudinal $z z$ stresses are reduced by the same proportion.

To avoid an increase of purely mechanical stresses in fillet radius 2, further design modification of the punch is required [13]. 


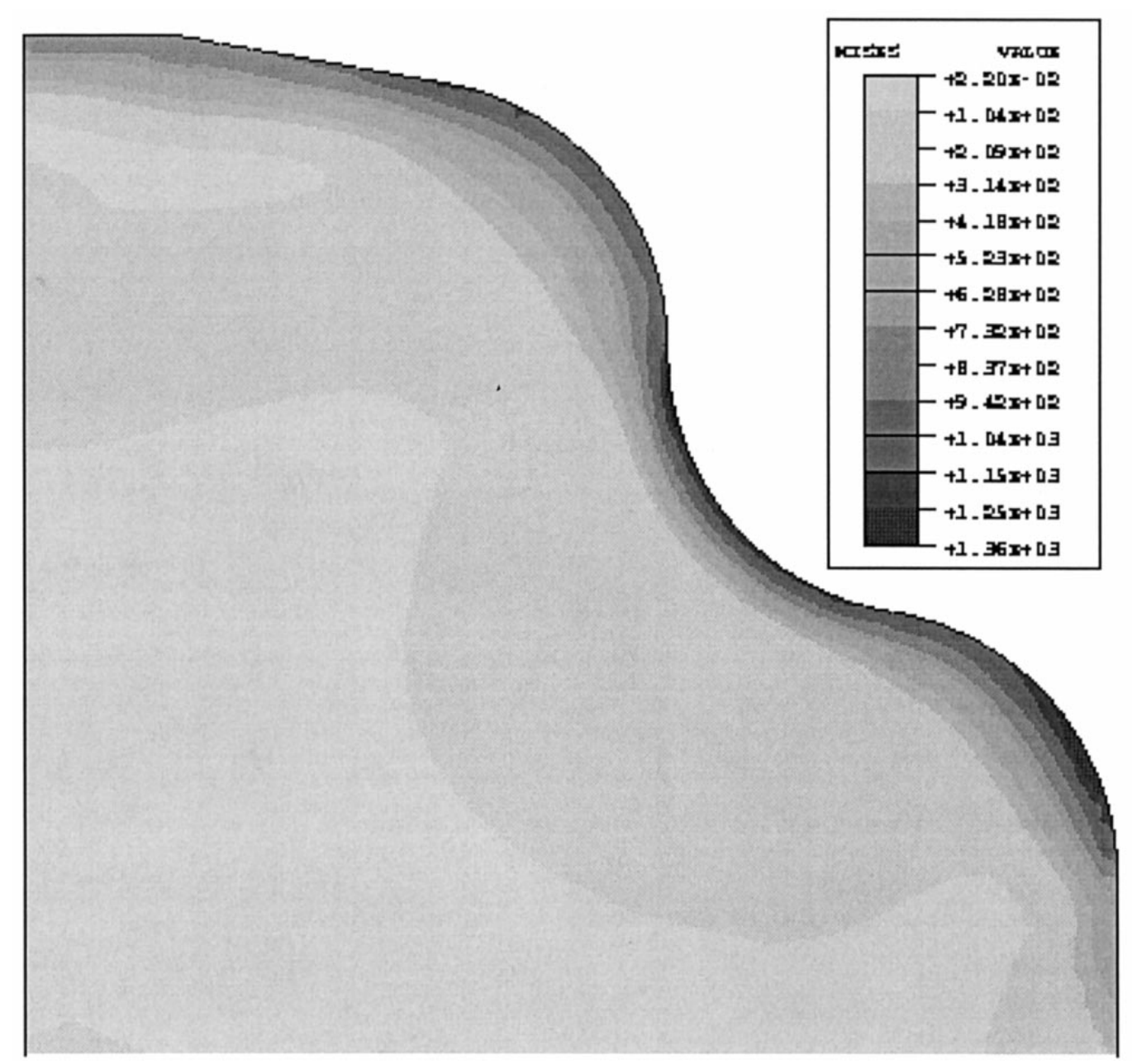

Fig. 13. Thermal stress distribution (MPa).

\section{Conclusions}

The lifetime of hot forging dies is often shortened by surface cracking and subsequent material splitting. This has been observed on a punch used in a one-step forward/backward hot forging process.

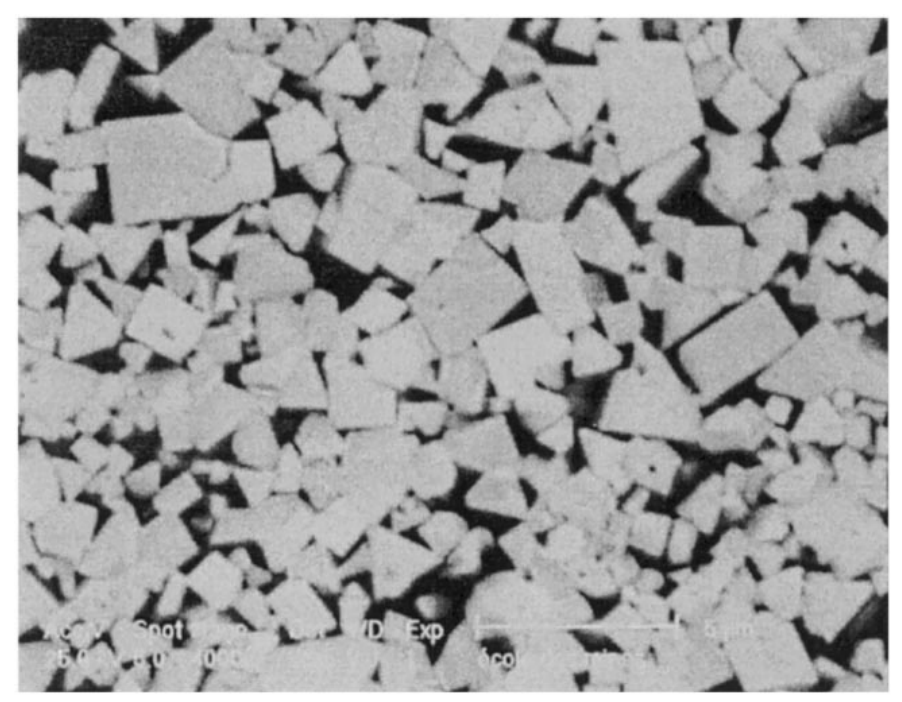

Fig. 14. 85-15 WC-Co microstructure.
This work describes the methodological approach that has been applied to study the reasons for the crack formation and to propose a solution to increase the lifetime.

A combined numerical and experimental approach is mandatory:

1. A two-step numerical simulation: first, process simulation allows the calculation of purely mechanical stresses, forging load and punch thermal boundary conditions; second, thermo-elastic simulation for thermal stress analysis of the punch.

2. A two-step experimental work: metallurgical observation allows the validation of workpiece material constitutive laws and industrial tests allow punch thermal boundary conditions.

It has been shown that thermal stresses, induced by the sharp thermal gradient during forging, correspond to $75 \%$ of the total stress field in the areas of surface cracking. After a parametric analysis, a modification of the forging process parameters (workpiece temperature and punch velocity) has been proposed.

This work clearly shows the benefits of a methodology based on combined numerical and experimental approaches to determine the thermomechanical stress 


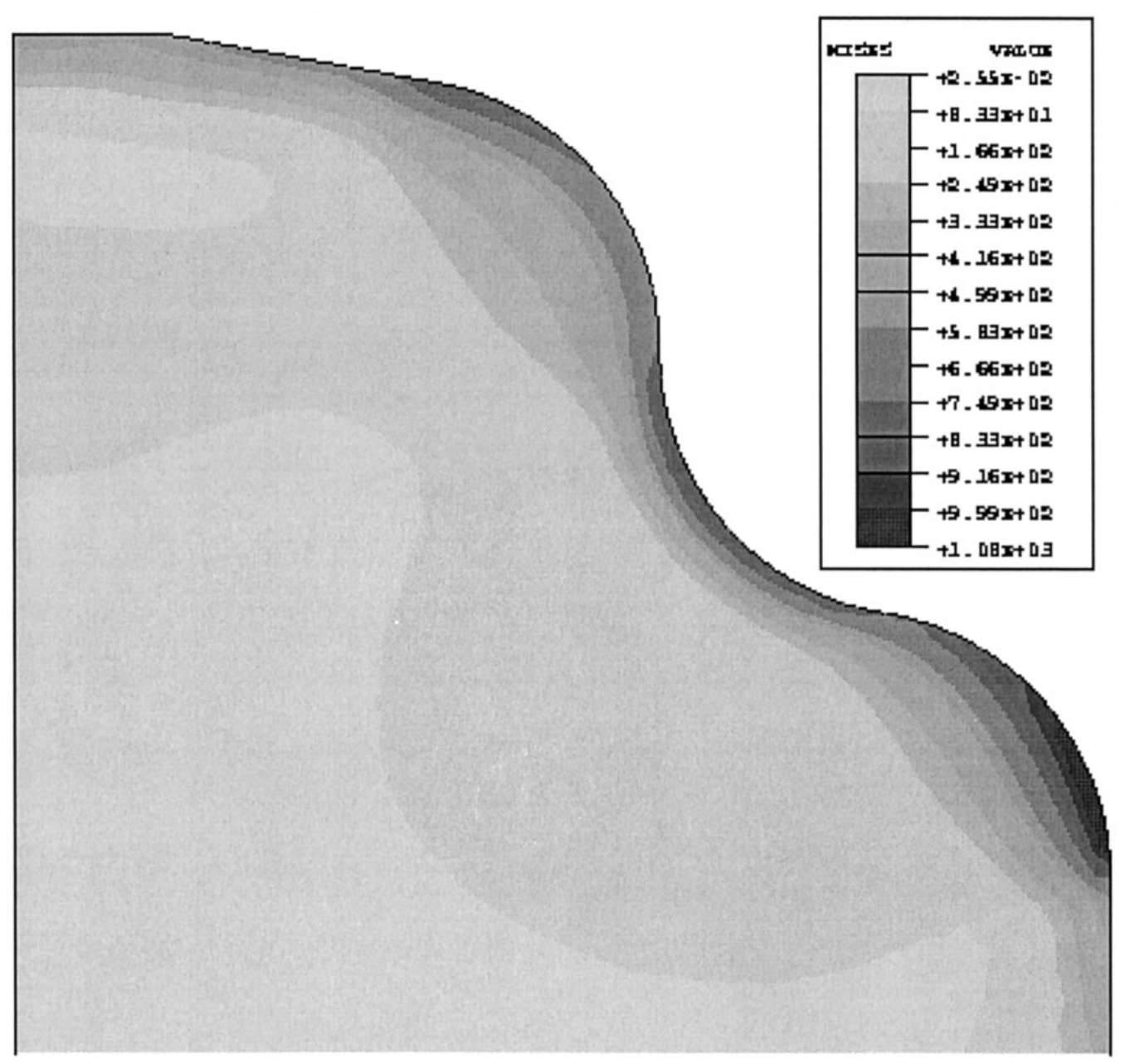

Fig. 15. Resulting thermal stress distribution (MPa).

field in hot forging tools, and, consequently to derive solutions for lifetime increase.

\section{Acknowledgements}

The authors would like to acknowledge Mr. Series from the company Mécaero for his financial and technical support to this study.

\section{References}

[1] T.B. Herlan, Les pièces forgées: Allégées mais plus performantes, Rev. Métall.-CIT 90 (10) (1993) 1265-1276.

[2] K. Lange, A. Hettig, M. Knoerr, Increasing tool life in cold forging through advanced design and tool manufacturing techniques, J. Mater. Process. Technol. 35 (1992) 495-513.

[3] S.I. Oh, W.T. Wu, J.P. Tang, Simulations of cold forging processes by the DEFORM system, J. Mater. Process. Technol. 35 (1992) 357-370.

[4] O. Brucelle, Amélioration de la durée de vie d'un outillage de matriçage, EMAC internal student report, 1996.
[5] D.A. Spera, What is thermal fatigue? Thermal fatigue of materials components, ASTM, Am. Soc. Testing Mater., Soc. Technol. Plast. 612 (1976) 3-9.

[6] A.Dias, H.P. Lieurade, La fatigue thermique, mécanismes, simulation et modélisation, Revue Bibliographique, IRSID, RFP 437, mai 1987.

[7] FORGE2 ${ }^{\circledR}$ v.2.7 Bidimensional Forging Processes; Transvalor SA; user manual, November 1994.

[8] B. Snaith, S.D. Probert, P.W. O'Callaghan, Thermal resistances of pressed contacts, Appl. Energy 22 (1986) 31-84.

[9] Z. Malinowski, J.G. Lenard, M.E. Davies, A study of the heat transfer coefficient function of temperature and pressure, J. Mater. Process. Technol. 41 (1994) 125-142.

[10] H. Doi, Elastic and Plastic Properties of WC-Co Composite Alloys, Freund, Israel, 1974, pp. 3-109.

[11] G. Fantozzi, H. SiMohand, G. Orange, High temperature mechanical behaviour of WC $-6 \mathrm{wt} . \%$ Co cemented carbide, $2 \mathrm{nd}$ Int. Conf. Science Hard Materials, no. 75, chapter 7, Rhodes, 1986, pp 699-712.

[12] P. Lair, J. Dumoulin, G. Bernhart, P. Millan, Etude numérique et expérimentale de la résistance thermique de contact à hautes températures et pression élevées, SFT 97, 20-22 mai 1997, Toulouse.

[13] Y. Nagao, M. Knoerr, T. Altan, Improvement of tool life in cold forging of complex automotive parts, J. Mater. Process. Technol. 46 (1994) $73-85$. 